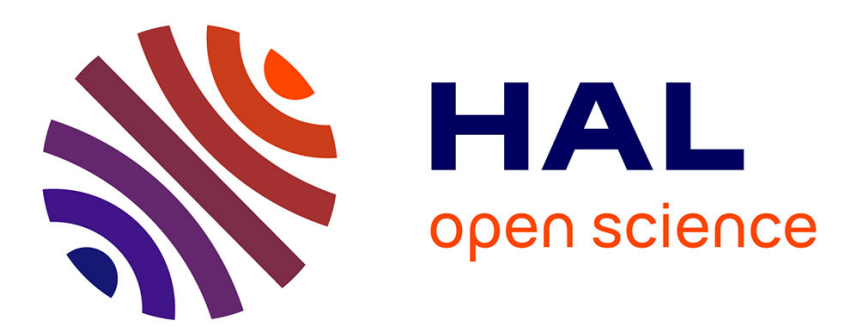

\title{
Carbon beads with a well-defined pore structure derived from ion-exchange resin beads
}

Ping He, Kok-Giap Haw, Shichen Yan, Lingxue Tang, Qianrong Fang, Shilun Qiu, Valentin Valtchev

\section{- To cite this version:}

Ping He, Kok-Giap Haw, Shichen Yan, Lingxue Tang, Qianrong Fang, et al.. Carbon beads with a well-defined pore structure derived from ion-exchange resin beads. Journal of Materials Chemistry A, 2019, 7 (31), pp.18285-18294. 10.1039/C9TA04069B . hal-03040601

\section{HAL Id: hal-03040601}

https://hal-normandie-univ.archives-ouvertes.fr/hal-03040601

Submitted on 4 Dec 2020

HAL is a multi-disciplinary open access archive for the deposit and dissemination of scientific research documents, whether they are published or not. The documents may come from teaching and research institutions in France or abroad, or from public or private research centers.
L'archive ouverte pluridisciplinaire HAL, est destinée au dépôt et à la diffusion de documents scientifiques de niveau recherche, publiés ou non, émanant des établissements d'enseignement et de recherche français ou étrangers, des laboratoires publics ou privés. 


\title{
Carbon beads with well-defined pore structure derived from ion- exchange resin beads
}

Received 00th January 20xx, Accepted 00th January 20xx

DOI: $10.1039 / x 0 x x 00000 x$

\author{
Ping He, ${ }^{a}$ Kok-Giap Haw, ${ }^{\text {a }}$ Shichen Yan, ${ }^{\text {a }}$ Lingxue Tang, ${ }^{a}$ Qianrong Fang, ${ }^{\text {a }}$ Shilun Qiu, ${ }^{\text {a }}$ Valentin \\ Valtchev $^{a, b^{*}}$
}

\begin{abstract}
Carbon beads were prepared by using two types, a microporous and a macroporous, of cation exchange resin beads as precursors. The beads were subjected to potassium exchange prior to the carbonization reaction at high temperature. The physicochemical properties of the obtained carbon beads were thoroughly studied to evaluate the impact of all key parameters: i) the type of cation exchange resin; ii) the concentration of $\mathrm{K}^{+}$in the resin beads, and iii) the carbonization temperature. The beads prepared from macroporous resin showed narrow pore size distribution, higher specific surface area and retained a spherical shape. These beads showed impressive $\mathrm{CO}_{2}$ adsorption capacity at ambient temperature and variable pressure and excellent performance in the decontamination of water from medical pollutant. The method of preparation can be easily scaled up, and thus prepared carbon beads can be used for other adsorption applications where shaped bodies with high specific surface area and large pore volume are needed.
\end{abstract}

\section{Introduction}

The environmental deterioration, mainly due to global warming and waste discharge, is the highest priority issue for the modern society. ${ }^{1-3}$ Global warming is namely due to the $\mathrm{CO}_{2}$ release in the atmosphere. On the other side, the discharge of wastewater from the agriculture and medical industries pollute the surface and underground waters with antibiotics and other harmful chemicals which threaten animals, plants and human health through direct or indirect exposure. One of the most common antibiotic present in environmental water bodies is Oxytetracycline. ${ }^{4}$ To overcome these environmental crises, constant efforts are targeted in the development of effective and sustainable methods to sequestrate the chemical contaminants and $\mathrm{CO}_{2}$ worldwide. Among them, the selective adsorption has been proven as an efficient and versatile method to purify gaseous and liquid phases. Through the years, a large variety of porous materials, offering large specific surface area and particular chemical selectivity, have been studied as adsorbents. Zeolites, ${ }^{5-7}$ ordered mesoporous silica, ${ }^{8,} 9$ porous carbonaceous adsorbents $^{10,11}$ and metal-organic frameworks (MOFs) ${ }^{12,13}$ are amongst the most widely investigated ones.

Porous carbonaceous adsorbents, due to their unique properties such as very high specific surface area, high hydrophobicity, variable pore structure, and availability, showed great potential for long-term industrial application. ${ }^{14}$

\footnotetext{
a. State Key Laboratory of Inorganic Synthesis and Preparative Chemistry, Jilin University, Changchun 130012, China.

${ }^{b .}$ Normandie Univ, ENSICAEN, UNICAEN, CNRS, Laboratoire Catalyse et

Spectrochimie, 6 Marechal Juin, 14050 Caen, France.

E-mail: valentin.valtchev@ensicaen.fr

Electronic Supplementary Information (ESI) available: [details of any supplementary information available should be included here]. Se DOI: $10.1039 / \times 0 \times x 00000 x$
}

${ }^{19}$ However, carbonaceous adsorbent like activated carbon in fine powder form could lead to operational concerns like secondary pollution ${ }^{20}$ and high pressure drop ${ }^{21}$ which limits its application. Therefore, carbon materials with controlled macroscopic shape, for instance, beads, are highly desired since they can meet the requirements of most industrial applications. ${ }^{22-27}$ Activated carbon beads can find different applications, for instance, can be used for $\mathrm{CO}_{2}$ uptake in swing adsorption experiments. ${ }^{28,} 29$ Tagliavini et al. studied the mechanisms of steroid micropollutants removal with polymerbased spherical activated carbon; ${ }^{2}$ and Zeng et al. conducted water evaporation and oil sorption on hydrophobic hollow carbon beads by phase inversion method. ${ }^{30,31}$ Wickramaratne et al. reported the importance of micropore size in activated carbon for the efficient $\mathrm{CO}_{2}$ capturing under ambient conditions. ${ }^{32}$ Various kind of functionalized activated carbon beads with the goal to target specific application have been reported in the literature. ${ }^{33-36}$ Preparation methods such as steam, ${ }^{37} \mathrm{CO}_{2}{ }^{28,}{ }^{38} \mathrm{ZnCl}_{2}{ }^{39}$ and $\mathrm{KOH}$ activations ${ }^{32,40}$ have been intensively studied and optimized to prepare carbon materials with high surface areas and appropriate pore structure for selective removal of target contaminant substances. However, the complicated post-synthesis modification procedures are time and cost consuming which limit the large-scale production of carbon spheres commercially. Consequently, much attention was paid to simplify the preparation of activated carbon. Singh et al. reported a single-step activation by mixing of an activating agent (solid $\mathrm{KOH}$ and $\mathrm{ZnCl}_{2}$ ) with biomass. The prepared activated biocarbon featured high BET surface area and decent microporosity, but lack of welldefined morphology and particle size. ${ }^{41,42}$ At present, there is no well-established synthetic strategy to prepare carbon beads with desired particle size and uniform pore size distribution. Therefore, a novel and efficient strategy to fabricate efficiently porous carbon spheres is highly desirable. An avenue that could be explored is the use of shaped polymer beads as a 
precursor of the activated carbon beads. Among the industrially available shaped polymer beads, cation exchange resin beads are probably the most appropriate candidate to fulfil such requirement. They can be prepared with different size and pore structure. In addition, they offer uniformly distributed ion exchange sites that allow the introduction of an activator that favors the carbonization reaction and thus the pore structure of resultant carbon beads.

The objective of the present study is the preparation of carbon beads with a well-defined spherical shape and microporous structure which can be potentially used as an adsorbent for efficient $\mathrm{CO}_{2}$ and medical pollutants capturing. We have selected millimeter-sized cation exchange resin bead as starting materials, justified by its proper particle size and morphology and also the possibility to select initial beads with different pore sizes, either micro- or macroporous. The pore structure of cation exchange resin beads offers the advantage to distribute the activator uniformly, in our case potassium, and thus to ensure a very uniform carbonization reaction. Both microporous gel-type (GCB) and macroporous (MSC) resin beads were subjected to ion exchange with $\mathrm{KCl}$ solutions of different concentration and carbonized at 700 to $1000{ }^{\circ} \mathrm{C}$ in order to optimize the pore structure of the resultant carbon beads. Carbon spheres with defined shape and size, high specific surface area and uniform micro- and mesopores network were obtained. These macroscopic carbon spheres showed excellent $\mathrm{CO}_{2}$ adsorption capacity and great ability of medical pollutant removal from aqueous solutions.

\section{Experimental}

\section{Materials}

All reagents were obtained from commercial sources and used without further purification. Gel-type microporous cation exchange resin beads (Dowex ${ }^{\circledR} 50 \mathrm{WX} 2, \mathrm{H}$-form) and macroporous cation exchange resin beads (Dowex ${ }^{\circledR} \mathrm{MSC}, \mathrm{H}-$ form) were purchased from Aldrich Corp. $\mathrm{KCl}(99 \%), \mathrm{HCl}(37 \%)$ and oxytetracycline dihydrate (OTC, 99\%) were purchased from Shanghai Chemical Corp. (China). A Milli-Q integral ultrapure water system was employed to produce deionized (DI) water, which was used in all experiments.

\section{Potassium exchange of resin beads}

$2.0 \mathrm{~g}$ raw resin beads were added into $80.0 \mathrm{~mL} \mathrm{KCl}$ aqueous solution and heated under stirring for $6 \mathrm{~h}$ at $60{ }^{\circ} \mathrm{C}$, and the exchange process were repeated three times with fresh $\mathrm{K}$ containing solution. The concentrations of the $\mathrm{KCl}$ solutions were $0.1 \mathrm{M}, 0.3 \mathrm{M}, 0.5 \mathrm{M}$ and $1.0 \mathrm{M}$, respectively. Then, the Kexchanged resin beads were separated by suction filtration, rinsed with water and dried overnight in an oven at $60^{\circ} \mathrm{C}$.

\section{Carbonization}

$0.1 \mathrm{~g} \mathrm{~K}$-exchanged resin beads were placed on a ceramic boat and transferred into a horizontal quartz tube reactor. Porous carbon beads were prepared by one-pot carbonization and activation at $700,800,900$ and $1000{ }^{\circ} \mathrm{C}$ for $2 \mathrm{~h}$ at a ramp rate of $3^{\circ} \mathrm{C} \mathrm{min}^{-1}$ under an ultrahigh pure $\mathrm{N}_{2}(99.999 \%)$ with a flow rate of $50 \mathrm{~mL} \mathrm{~min}{ }^{-1}$. The obtained carbon beads were thoroughly washed with $1 \mathrm{M} \mathrm{HCl}$ in an ultrasonic bath to completely remove the residues followed by washing with DI water several times till the $\mathrm{pH}$ value reaches 7 . The porous carbon beads were dried overnight in an oven at $60^{\circ} \mathrm{C}$. Porous carbon beads prepared from microporous gel-type Dowex ${ }^{\circledR}$ 50WX2 and macroporous Dowex ${ }^{\circledR}$ MSC resin beads were labelled as GCB-m-t and MSC-m- $t$ respectively, where $m$ is the concentration of $\mathrm{KCl}$ solution (in $\mathrm{mol} \mathrm{L}^{-1}, \mathrm{M}$ ) and $t$ is the carbonization temperature in ${ }^{\circ} \mathrm{C}$. For comparison purpose, two control samples were prepared from Dowex ${ }^{\circledR} 50 \mathrm{WX} 2$ and Dowex ${ }^{\circledR} \mathrm{MSC}$ resin beads at $900^{\circ} \mathrm{C}$ without preliminary $\mathrm{KCl}$ exchange and labelled as GCB-0-900 and MSC-0-900, respectively.

\section{Characterization}

Powder X-ray diffraction (PXRD) analysis was performed on a PANalytical B.V. Empyrean powder diffractometer at $40 \mathrm{kV}$ and $40 \mathrm{~mA}$ using $\mathrm{Cu} \mathrm{K} \alpha$ radiation $(\lambda=1.5418 \AA$ ) over the range of $2 \theta=10.0-80.0^{\circ}$. Confocal Raman spectra were measured using a RENISHAW invia Raman Microscope equipped with an argon-ion laser ( $514.5 \mathrm{~nm}$ ). A JEOL JSM-6510 scanning electron microscope was used to study the morphology of the samples. Transmission electron microscopy (TEM) analysis was carried out on a JEM-2100 microscope. Before PXRD, TEM and Raman analysis, the microspheres were ground into powder in an agate mortar. $\mathrm{CO}_{2}$ adsorption was performed on a Quantachrome Autosorb-IQ analyzer with ultra-high-purity grade $\mathrm{CO}_{2}(99.999 \%)$ at $273 \mathrm{~K}$ and $298 \mathrm{~K}$. High-pressure $\mathrm{CO}_{2}$ adsorption was performed on a home-built HPSA-2 instrument made by Shanghai University. Nitrogen adsorption analysis was performed on a Micromeritics ASAP 2460 volumetric adsorption analyzers with ultra-high-purity grade $\mathrm{N}_{2}$ (99.998 $\%)$ at $77 \mathrm{~K}$. Prior to the analysis, the samples were outgassed at $300{ }^{\circ} \mathrm{C}$ for $12 \mathrm{~h}$. The specific surface area of the carbon beads was calculated using Brunauer-Emmett-Teller (BET) method within the relative pressure $\left(P / P_{0}\right)$ range of $0.05-0.25 .{ }^{43}$ The total pore volume $\left(\mathrm{V}_{\text {total }}\right)$ was calculated from the amount of nitrogen adsorbed at $\mathrm{P} / \mathrm{P}_{0}$ of ca. 0.99. The micropore volume was determined by the t-plot method. The pore size distributions were calculated using density functional theory (DFT) and Barrett-Joyner-Halenda theory (BJH) method, respectively. ${ }^{44,}$ A SHIMADZU UV-2450 spectrophotometer was used to analyze the concentration of OTC during adsorption tests.

\section{Results and discussion}

\section{Structure and morphology analysis}

Cation exchange resin beads with gel-type microporous (GCB) and macroporous (MSC) structures were chosen as precursors. The building units in these two types of resin are similar (Scheme S1), however their structural organization is different. MSC resin exhibits large pores and highly accessible surface, which facilitates the removal of charged species from different solvents. In the case of the GCB resin, since it has no discrete pores, only solute ions could diffuse through the gel network and interact with the exchange sites. It is expected that 
different structural organization would lead to different diffusion paths during the carbonization process and thus carbon beads with different pore structure could be obtained.

In both ion exchange resins, sulfonic functional groups (Scheme S1) are present as cation exchange sites. Carbonization of polymer precursors using $\mathrm{KOH}$ activation has been extensively studied in the past. ${ }^{24,46,47}$ In the present study we implemented $\mathrm{KCl}$ as the activation agent. The activation efficiency of $\mathrm{KCl}$ is similar to the conventionally used $\mathrm{KOH}$. On the other side, the $\mathrm{KCl}$ offers the advantage to be moderate, neutral and thus environmentally benign. During the ion exchange, the proton of the sulfonic acid functional groups was exchanged to $\mathrm{K}^{+}$. After the exchange, the potassium is uniformly distributed in the resin network as can be seen in Fig. S1. The potassium content is almost equal to the sulfur content which confirms the homogeneous distribution of potassium ions (Fig. S2a). In the following carbonization step, $\mathrm{K}^{+}$cations play the role of activator which leads to oxidation of carbon and decomposes the hydrocarbons into $\mathrm{H}_{2}, \mathrm{CO}, \mathrm{CO}_{2}$ and $\mathrm{H}_{2} \mathrm{O}$. The generate gas diffuse within the carbon matrix and contribute to porosity development. ${ }^{41,48}$ The chemical and thermal activation happens simultaneously maximizing the efficiency of the reaction and the development of porosity. During the conversion of the ion exchange into carbon beads, a part of the organic skeleton is lost. Nevertheless, a substantial part of the carbon is preserved since our measurements showed conversion between 30 and $50 \%$, as the lower yield was in the case of GCB-0.3-1000 (30\%) and the higher yield in the case of MSC-0.1-1000 (51\%).

Fig. 1a shows the typical XRD patterns of the activated carbon beads obtained under different conditions. In general, the XRD patterns exhibit two broad peaks at about $24.0^{\circ}$ and $44.0^{\circ}$, characteristic of non-graphitic carbon, which is in agreement with the Raman data (Fig. $1 \mathrm{~b}$ and 1c). Raman spectra showed two well defined peaks at 1360 and $1585 \mathrm{~cm}^{-1}$ for all studied samples (Fig. 1b, 1c and Fig. S3). These bands correlate well with the disordered (D-band) and ordered (G- band) crystal structures of graphite, respectively. ${ }^{49}$ The intensity ratio $\left(I_{D} / I_{G}\right)$ of these bands is almost similar (around 0.96-1.06) in all samples and reflect the low degree of graphitization for carbon beads. The Raman study also revealed that the level of graphitization does not correlate with the concentration of $\mathrm{KCl}$ (Fig. 1b) and the carbonization temperature (Fig. 1c).

In general, the carbon beads retained the spherical shape of the precursor, but the level of integrity of obtained carbon beads and the surface porosity strongly depend on the type of cation exchange resin employed and the $\mathrm{K}^{+}$content. Fig. S4 shows that the carbon beads obtained from GCB resin are broken with a rough surface and large macropores, as the central part of the beads is often missing. This result points out the violence of the reaction in the volume of the gel type resin beads, where no well define pore are present. The high pressure generated in the volume of the beads results in their disintegration, as shell parts with hemi-spherical morphology remain. The core part is missing, which is probably due to the disintegration into very small pieces. No substantial difference was observed between the beads activated at different temperatures (Fig. S4a-d). It should be noted that $\mathrm{K}^{+}$obviously promote the carbonization reaction. This result reveals that the gel-type resin is not an appropriate precursor for preparation of carbon beads since the absence of pores obstructs the release of generated gases $\left(\mathrm{H}_{2}, \mathrm{H}_{2} \mathrm{O}\right.$ steam, CO and $\mathrm{CO}_{2}$ ) during carbonization reaction.

Fig. 2 shows representative SEM micrographs of carbon beads obtained from MSC resin beads after $0.1 \mathrm{M} \mathrm{KCl}$ exchange and carbonization at different temperatures. Different to the ones derived from GCB resin beads, these carbon beads exhibited well-defined spherical morphology (Fig. 2a, c, e, g). Small craters can be observed on the surface, which is due to the gas release during carbonization (Fig. 2b, d, $f, h)$. The retained morphology of the carbon beads is obviously due to the presence of large well-defined pores which ensure the efficient release of generated gases. The presence of these pores in the carbon beads is also essential.
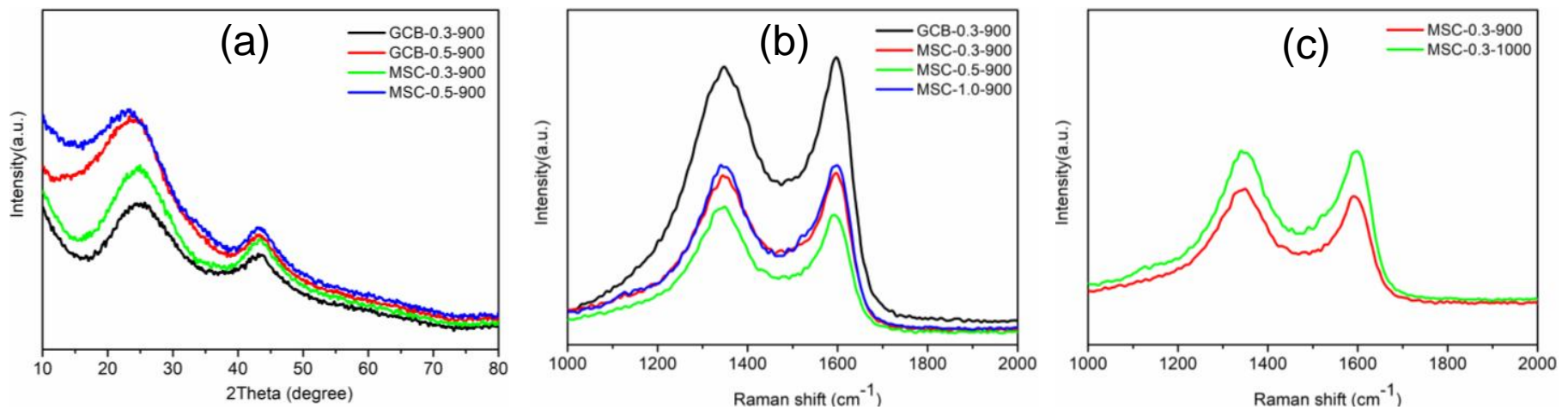

Fig. 1 (a) PXRD patterns of GCB-0.3-900, GCB-0.5-900, MSC-0.3-900 and MSC-0.5-900 activated carbon beads. Raman spectra of: (b) GCB-0.3-900, MSC-0.3-900, MSC-0.5-900, and MSC-1.0-900 activated carbon beads, and (c) MSC-0.3-900 and MSC-0.3-1000 activated carbon beads. 

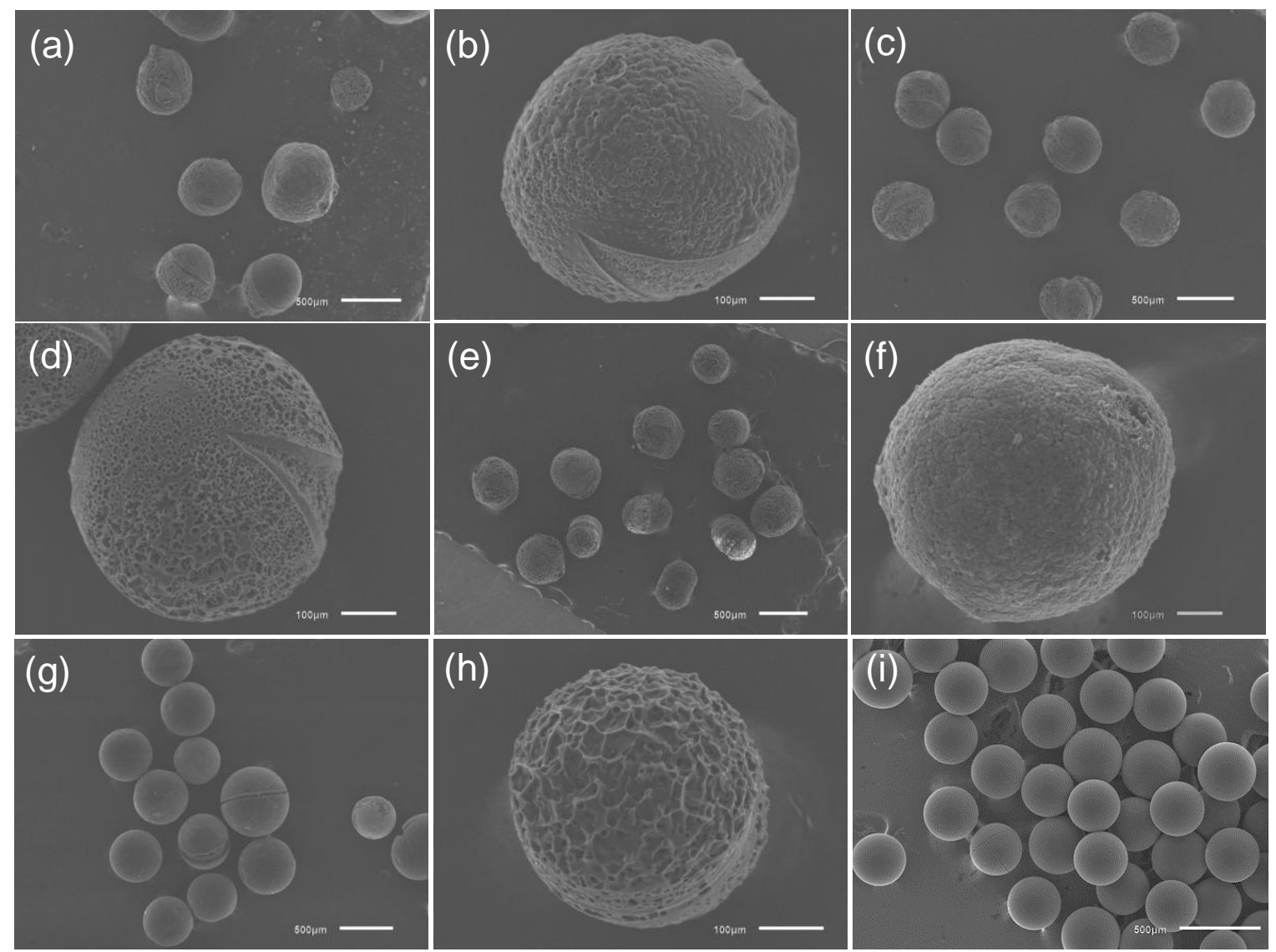

Fig. 2 Low- and high-resolution SEM micrographs of (a, b) MSC-0.1-700, (c, d) MSC-0.1-800, (e, f) MSC-0.1-900, (g, h) MSC-0.1-1000 activated carbon beads obtained from MSC resin beads and (i) MSC-0-900 reference sample obtained without preliminary exchange with potassium.

for the envisaged sorption applications. ${ }^{17,} 32$ The reference sample retained the perfect spherical shape and smooth external surface of initial ion exchange beads (Fig. 2i). As mentioned, the $\mathrm{K}^{+}$plays essential role in the carbonization reaction, which is further demonstrated by the results obtained after potassium exchange with solutions of higher concentration

The carbon beads obtained after an exchange with $0.3 \mathrm{M}, 0.5$ $\mathrm{M}$ and $1.0 \mathrm{M} \mathrm{KCl}$ showed larger surface pores (Fig. 3). The beads obtained after an exchange with $0.5 \mathrm{M}$ and $1.0 \mathrm{M} \mathrm{KCl}$ are often elongated, thus the morphology changes from spherical to elliptical. Again, the pressure generated in the volume of the beads is the reason for these morphological changes. Although the macroporous beads contain large pores, a considerable amount of gas generated by significant amount of potassiumthat cannot be evacuated immediately and lead to the described morphological changes. This result shows the possibility to tune the morphology and the porosity (vide supra) of the carbon beads by the potassium content. Elemental analysis of the MSC-0.3-900 sample was performed by using EDS analyses operated on SEM instrument. As shown in Fig. 4 and Fig. S2b, carbon, and oxygen are the major elements in these porous carbons, indicating the complete removal of the inorganic parts $(\mathrm{K})$ after washing with $\mathrm{HCl}$. Morover, a certain amount of sulfur uniformly distributed in the beads remains in the carbon network. These sulfur functionalities may act as binding sites for adsorption as reported in the literature. ${ }^{50-53}$ The high resolution TEM image of MSC-0.3-900 (Fig. 5) reveals the amorphous structure of the carbon comprising 2-4 $\mathrm{nm}$ long graphitic layers.

\section{Porosity analysis}

The $\mathrm{N}_{2}$ adsorption-desorption isotherms of the obtained activated carbon beads are presented in Fig. 6. All samples show rapid uptake at low relative pressure, typical of microporous type material, followed by horizontal adsorption/desorption branches. The isotherms are a combination of type I and IV according to the IUPAC classification. The hysteresis loop is characteristic of slit-like textural pores.

The data calculated from the analysis of the isotherms are summarized in Table 1 . The obtained data reveals the impact of all variables, type of resin, the concentration of $\mathrm{KCl}$ solution and carbonization temperature, on the characteristics of carbon beads. Without the preliminary exchange of potassium, carbon beads with very low specific surface area and pore volume are obtained. The importance of $\mathrm{KCl}$ on the carbonization reaction was discussed already. However, the $\mathrm{N}_{2}$ adsorption data provide additional information about the impact of $\mathrm{KCl}$ concentration during the ion exchange. In general, an increase in the concentration of $\mathrm{KCl}$ leads to carbon beads with higher specific surface area and pore volume. The best results are obtained from $0.3 \mathrm{M} \mathrm{KCl}$ 

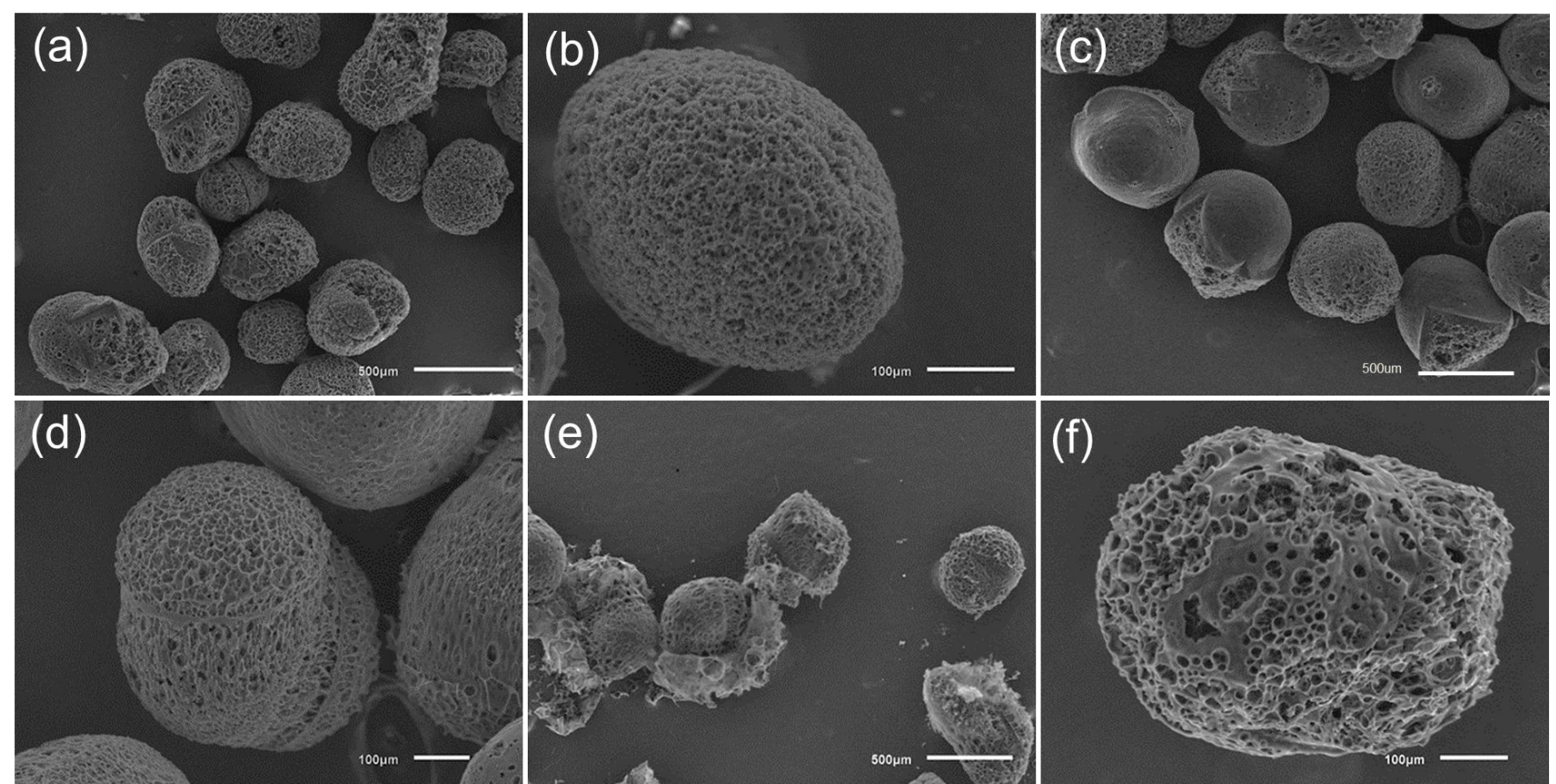

(e)
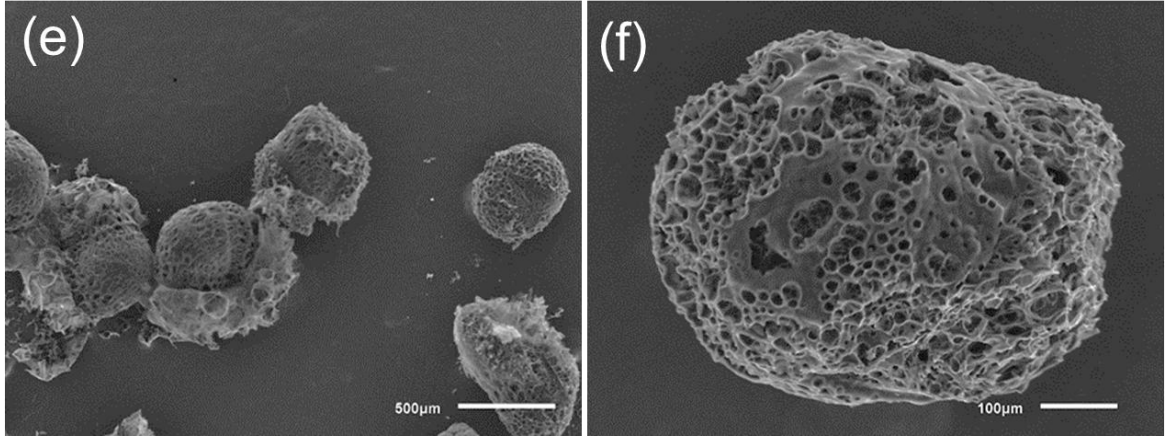

Fig. 3 Low and high magnification SEM micrographs of carbon beads obtained from MSC resin after potassium exchange with solutions of different concentration: (a, b) MSC-0.3-900, (c, d) MSC-0.5-900 and (e, f) MSC-1.0-900.

exchange resin beads with both gel-type and macroporous configuration. The increase of carbonization temperature from 700 to $900{ }^{\circ} \mathrm{C}$ led to the increase in BET surface area, total and micropore pore volume of the carbon beads (Table 1). Further elevated the temperature $\left(1000^{\circ} \mathrm{C}\right)$, however, leads to the drop in the pore volume and the specific (a)
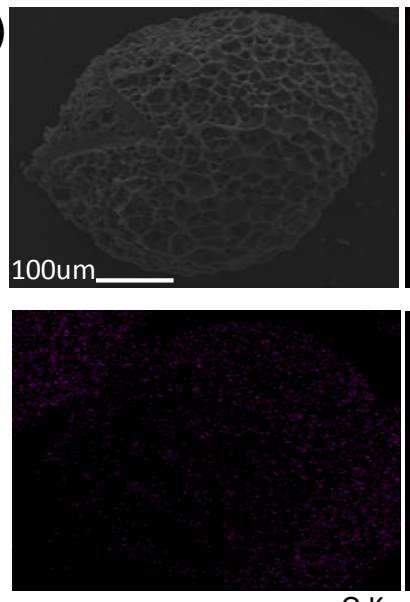
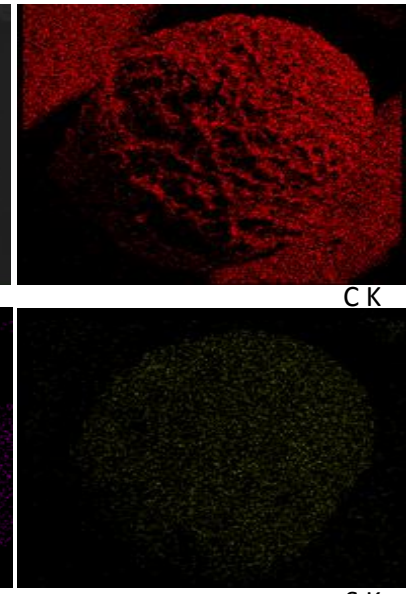

S K
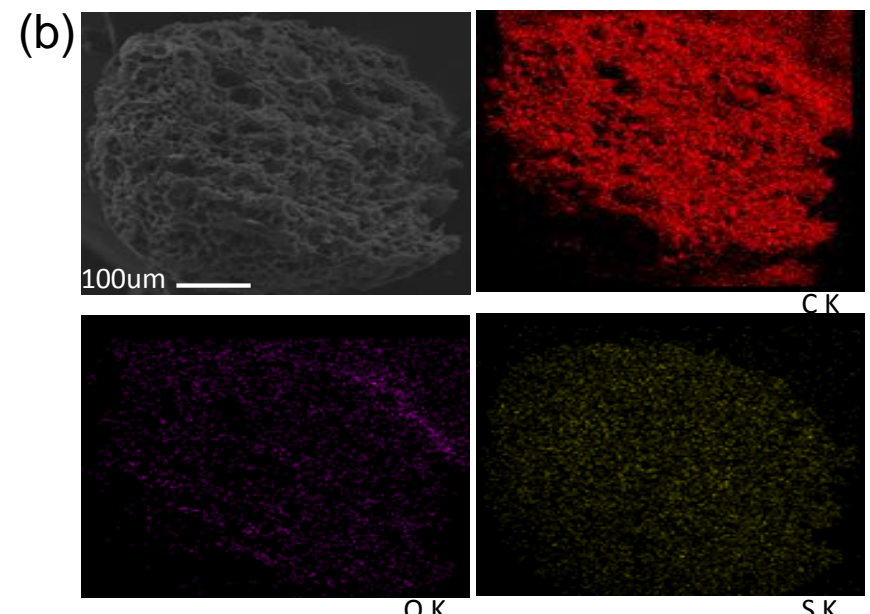

Fig. 4 EDS mapping MSC-0.3-900 carbon beads: (a) general view and (b) cross-section view. 


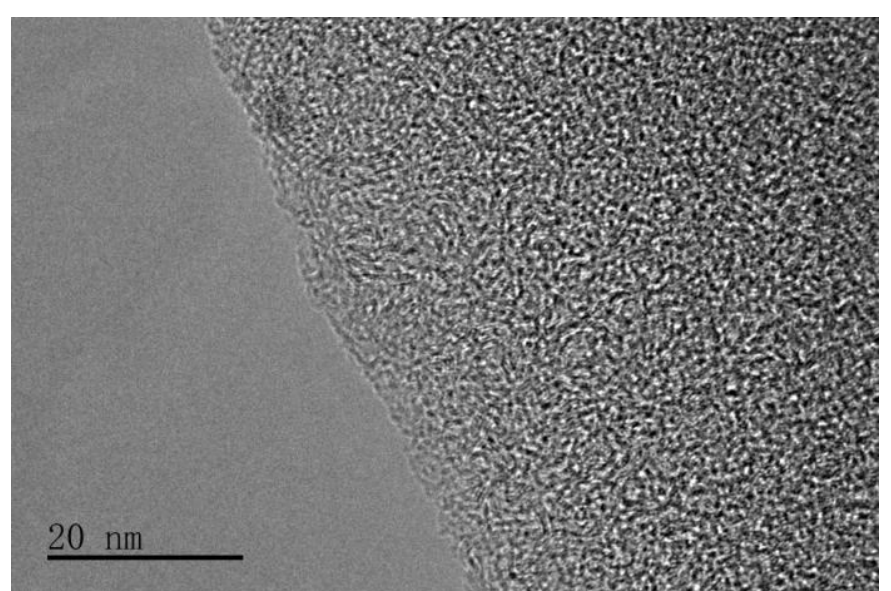

Fig. 5 High resolution TEM micrograph of the MSC-0.3-900 carbon beads.

surface area. The optimum conditions for the preparation of the activated carbon beads was ion exchange with $0.3 \mathrm{M} \mathrm{KCl}$ solution and carbonization at $900{ }^{\circ} \mathrm{C}$. Among all the samples, GCB-0.3-900 and MSC-0.3-900 showed the highest BET surface area $\left(909 \mathrm{~m}^{2} \mathrm{~g}^{-1}\right.$ and $\left.1398 \mathrm{~m}^{2} \mathrm{~g}^{-1}\right)$, microporous volume $(0.41$ $\mathrm{cm}^{3} \mathrm{~g}^{-1}$ and $\left.0.59 \mathrm{~cm}^{3} \mathrm{~g}^{-1}\right)$, and total pore volume $\left(0.49 \mathrm{~cm}^{3} \mathrm{~g}^{-1}\right.$ and $0.69 \mathrm{~cm}^{3} \mathrm{~g}^{-1}$ ), respectively. The DFT pore size distribution analysis showed micropore width with sizes majorly below 1.5 $\mathrm{nm}$ with a maxium at about $0.8 \mathrm{~nm}$ (Fig. S5). Small mesopores (2-4 $\mathrm{nm})$ with narrow pore size distribution were detected in the carbon beads derived from the GCB resin, while almost no mesopores were detected in the carbon beads derived from macroporous resin beads (Fig. 7 and Fig. S6).

\section{$\mathrm{CO}_{2}$ adsorption}

$\mathrm{CO}_{2}$ adsorption experiments were performed on the best, in terms of specific surface area and micropore volume, carbon samples. The $\mathrm{CO}_{2}$ adsorption capacities of the selected carbon beads were investigated at 273 and $298 \mathrm{~K}$ under atmospheric pressure ( 1 bar) as shown in Fig. 8a,b. MSC-0.3-900, the sample with the highest surface area and pore volume, displayed the highest $\mathrm{CO}_{2}$ uptake of 6.7 and $4.7 \mathrm{mmol} \mathrm{g}^{-1}$ at $273 \mathrm{~K}$ and $298 \mathrm{~K}$, respectively. Micropores with size between $0.8 \mathrm{~nm}$ and $1.3 \mathrm{~nm}$ are preferable for $\mathrm{CO}_{2}$ capture, owing to the stronger interactions between $\mathrm{CO}_{2}$ molecules and pore walls. $^{23,54-59}$ In the case of carbon obtained from ion exchange resin we anticipate an additional beneficial effect due to the presence of acidic groups generated by the remaining sulfur. ${ }^{51,}$ ${ }^{53}$ The analysis of the adsorption results shows a correlation between the $\mathrm{CO}_{2}$ capacity (Fig. 8a,b) and the micropore volume of carbon beads (Table 1). The best result was obtained with $\mathrm{MSC}$ resin beads pre-treated with $0.3 \mathrm{M} \mathrm{KCl}$ and carbonized at $900^{\circ} \mathrm{C}$ (Fig. $8 \mathrm{a}, \mathrm{b}$ ). It should be noted that the $\mathrm{CO}_{2}$ adsorption capacity of MSC-derived carbons is substantially higher than their counterparts obtained from GCB resin (Fig. 8a, b). Thus, the MSC-derived carbon beads with well-defined micropores proved to be an excellent $\begin{array}{llll}\text { adsorbent } & \text { for } & \mathrm{CO}_{2} & \text { capture. }\end{array}$
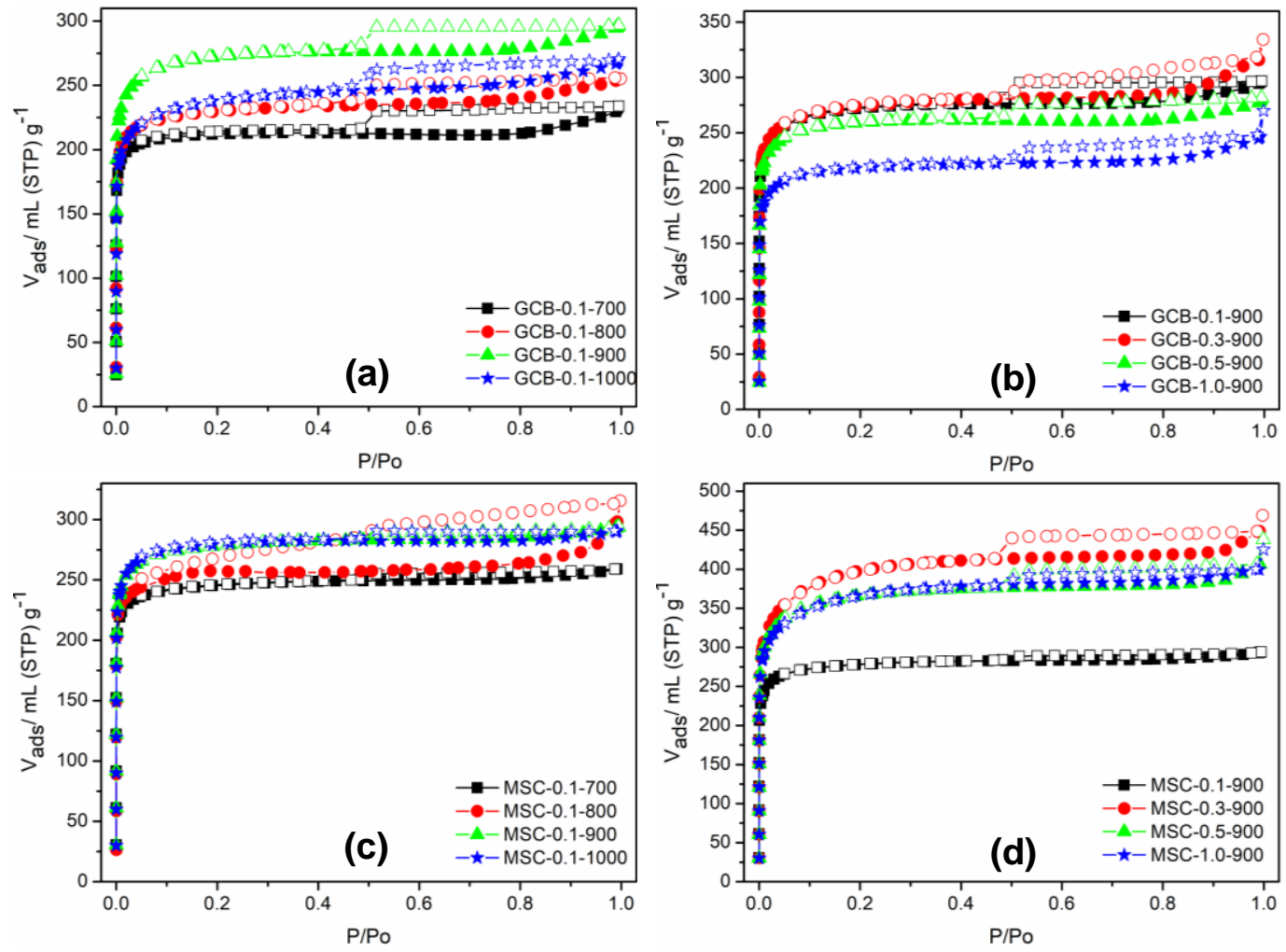

Fig. 6 Nitrogen adsorption-desorption isotherms of $\operatorname{GCB}(a, b)$ and MSC (c, d) activated carbon beads obtained after exchanged with KCl of different concentration and carbonized at different temperatures. 
Table 1 Surface and porous characteristics of the GCB and MSC activated carbon beads

\begin{tabular}{llll}
\hline Sample & $\mathrm{S}_{\text {BET }}\left(\mathrm{m}^{2} \mathrm{~g}^{-1}\right)$ & $\mathrm{V}_{\text {total }}\left(\mathrm{cm}^{3} \mathrm{~g}^{-1}\right)$ & $V_{\text {micro }}\left(\mathrm{cm}^{3} \mathrm{~g}^{-1}\right)$ \\
\hline GCB-0-900 & 36 & 0.06 & 0.02 \\
GCB-0.1-700 & 693 & 0.35 & 0.31 \\
GCB-0.1-800 & 759 & 0.39 & 0.33 \\
GCB-0.1-900 & 901 & 0.46 & 0.38 \\
GCB-0.1-1000 & 832 & 0.41 & 0.33 \\
GCB-0.3-900 & 909 & 0.49 & 0.41 \\
GCB-0.5-900 & 856 & 0.43 & 0.37 \\
GCB-1.0-900 & 720 & 0.38 & 0.31 \\
MSC-0-900 & 133 & 0.07 & 0.06 \\
MSC-0.1-700 & 803 & 0.40 & 0.38 \\
MSC-0.1-800 & 852 & 0.46 & 0.39 \\
MSC-0.1-900 & 921 & 0.45 & 0.43 \\
MSC-0.1-1000 & 918 & 0.45 & 0.42 \\
MSC-0.3-900 & 1398 & 0.69 & 0.59 \\
MSC-0.5-900 & 1229 & 0.63 & 0.56 \\
MSC-1.0-900 & 1220 & 0.62 & 0.52 \\
\hline & & &
\end{tabular}

Adsorbents that can efficiently adsorb $\mathrm{CO}_{2}$ at high pressure might be appropriate for high-density gas storage application. ${ }^{60}$ Therefore, we studied the $\mathrm{CO}_{2}$ sorption capacity at high pressure condition ranging from 1 bar to 26 bars at 298 $\mathrm{K}$ (Fig. 9). Ion exchange resin derived carbon beads shows impressive $\mathrm{CO}_{2}$ uptake at high pressure (26 bar), as the highest uptake at $298 \mathrm{~K}\left(14.7 \mathrm{mmol} \mathrm{g}^{-1}\right)$ of MSC-0.3-900 is comparable with that of recently published carbon materials obtained by $\mathrm{KOH}$ activation. ${ }^{41,42,60,61}$ GCB-0.3-900 derived from the geltype resin beads showed lower $\mathrm{CO}_{2}$ storage (Fig. 8), which is in accordance with its inferior pore structure (Table 1). The uptake mechanism at high pressure is more reliant to the available surface area and pore volume. ${ }^{56,61-63}$ Hence, the welldefined pore structure of carbon beads, with a remarkable proportion of micropores as well as the high surface area is more appropriate for $\mathrm{CO}_{2}$ capture and storage, no matter of the conditions employed.

The isosteric heat of adsorption $\left(Q_{s t}\right)$ is an important parameter providing information for the thermal performance of an adsorbent (Table 2). For the series of carbon beads subjected to $\mathrm{CO}_{2}$ adsorption (GCB-0.3-900, MSC-0.3-900, MSC0.5-900, MSC-1.0-900), the $\mathrm{Q}_{\mathrm{st}}$ was calculated using the Clausius-Clapeyron relation at $273 \mathrm{~K}$ and $298 \mathrm{~K}$ (Fig. S7). The value of $Q_{\text {st }}$ decreases with the adsorbed amount, which is characteristic of adsorbent-adsorbate systems based on weak Van der Waals interactions. The obtained result also reveals the heterogeneous nature of the adsorbing surface. The initial $\mathrm{Q}_{\mathrm{st}}$ of the carbon beads ranges from $28.0 \mathrm{~kJ} \mathrm{~mol}^{-1}$ to $30 \mathrm{~kJ} \mathrm{~mol}^{-}$ 1 , which is within the characteristic range of activated carbon materials. ${ }^{61}$ The difference between these two values is mainly due to the different strength of interaction between specific contact surfaces in the micropores and $\mathrm{CO}_{2}$ molecule.
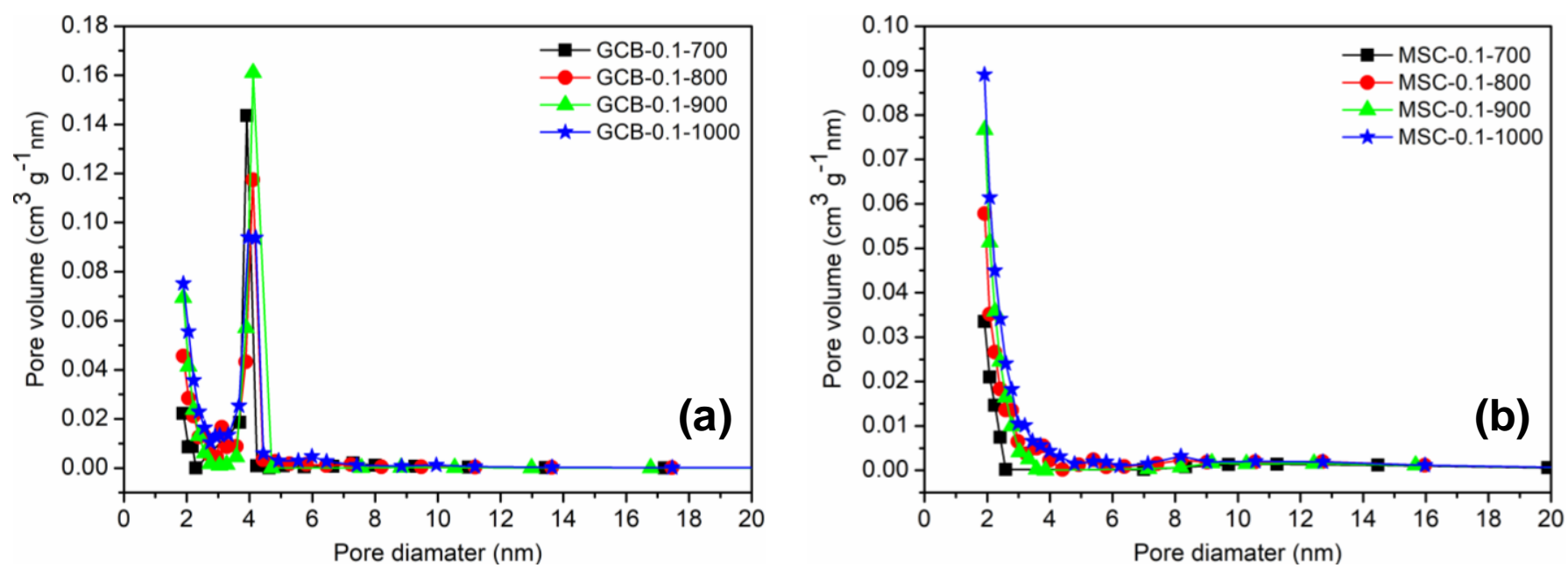

Fig. 7 BJH pore size distributions of (a) GCB and (b) MSC activated carbon beads. 

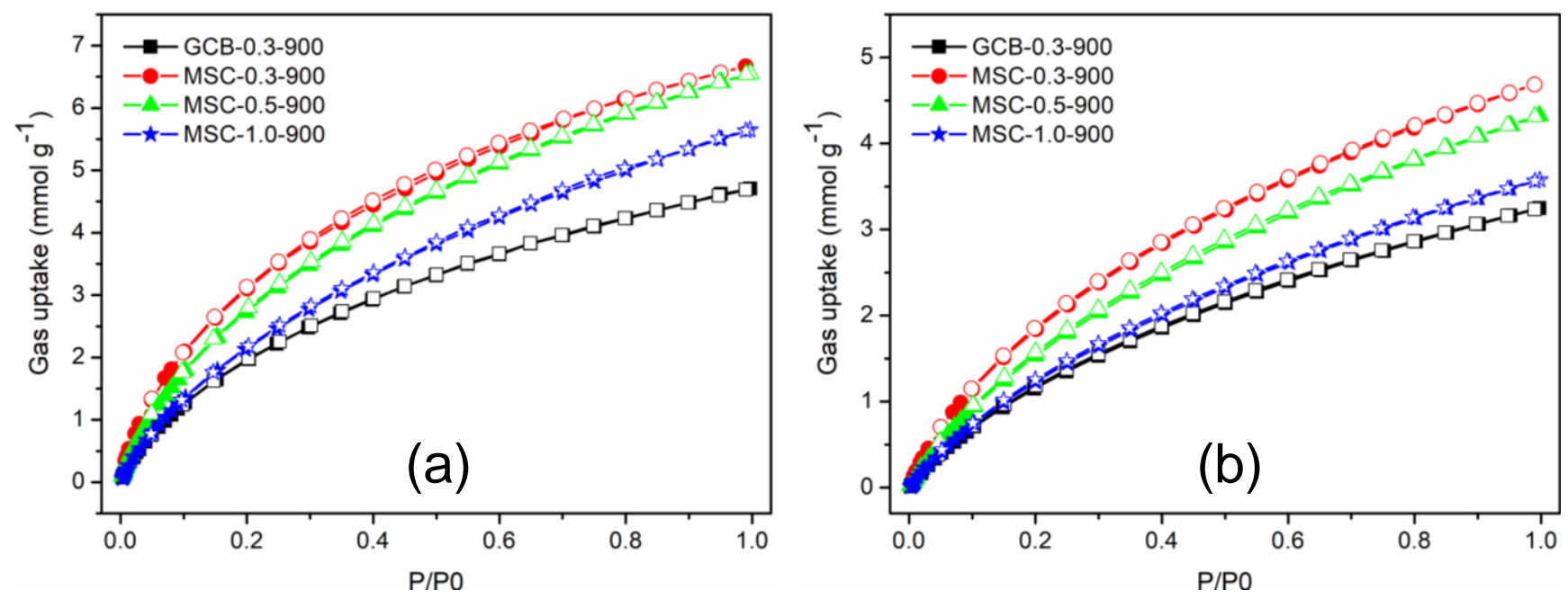

Fig. $8 \mathrm{CO}_{2}$ adsorption isotherms of activated carbon beads at (a) $273 \mathrm{~K}$ and (b) $298 \mathrm{~K}$ and 1 bar pressure.

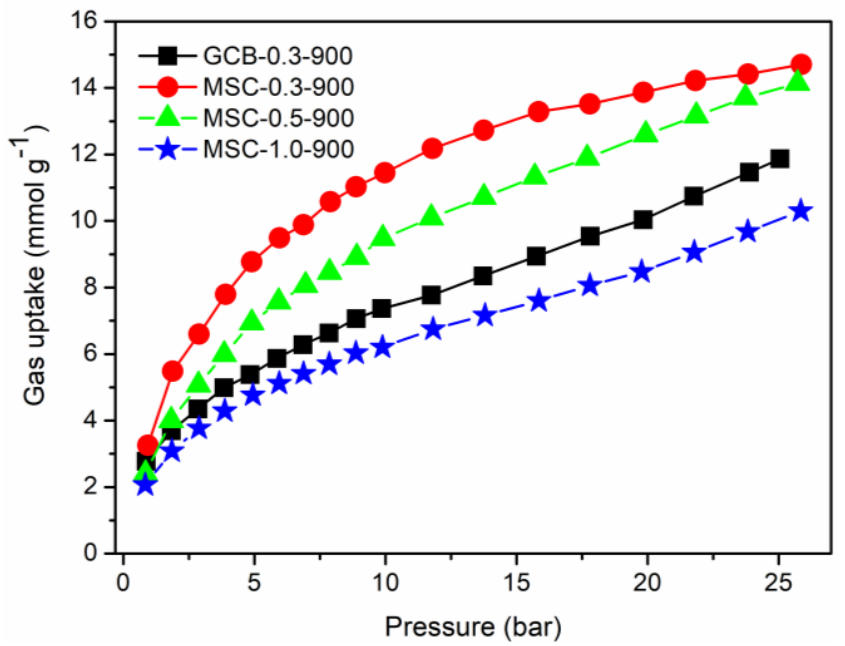

Fig. $9 \mathrm{CO}_{2}$ adsorption isotherms of activated carbon beads at $298 \mathrm{~K}$ and variable pressures.

\section{Oxytetracycline adsorption from aqueous solutions}

We studied the OTC adsorption ability of the activated carbon beads from aqueous solutions with concentrations ranging from 20 to $800 \mathrm{mg} \mathrm{L}^{-1}$. Each experiment was performed three times to verify the reproducibility of the results. Fig. 10 shows the OTC adsorption isotherms for the series GCB-0.3-900, MSC-0.3-900, MSC-0.5-900 and MSC-1.0-900 beads. The adsorption capacities increase with the incremental in OTC concentration. We interpret this result as a proof of the high capacity of the carbon beads combined with the good accessibility to the pore volume which enables fast transport and rapid uptake. All activated carbon beads exhibited remarkable adsorption capacity. For instance, the adsorption capacities with a solution of $800 \mathrm{mg} \mathrm{L}^{-1}$ were 320.1, 406.6, 382.0 and $386.0 \mathrm{mg} \mathrm{g}^{-1}$ for GCB-0.3-900, MSC-0.3-900, MSC0.5-900 and MSC-1.0-900 beads, respectively. Among them, GCB-0.3-900 activated carbon beads showed the lowest uptake, attributed to its lower specific surface area and micropore volume. These values were comparable to the

Table 2 Comparison of $\mathrm{CO}_{2}$ adsorption capacities and isosteric heat of adsorption $\left(\mathrm{Q}_{\mathrm{st}}\right)$ for a series of adsorbents reported in the literature and the best material obtained in the present study

\begin{tabular}{lllllll}
\hline Materials & $\begin{array}{l}\mathrm{S}_{\mathrm{BET}} \\
\left(\mathrm{m}^{2} \mathrm{~g}^{-1}\right)\end{array}$ & $\begin{array}{l}\mathrm{Q}_{\mathrm{st}} \\
\left(\mathrm{kJ} \mathrm{mol}^{-1}\right)\end{array}$ & $\begin{array}{l}\text { Pressure } \\
(\mathrm{bar})\end{array}$ & $\begin{array}{l}\text { Temperature } \\
(\mathrm{K})\end{array}$ & $\begin{array}{l}\text { Capacity } \\
\left(\mathrm{mmol} \mathrm{g}^{-1}\right)\end{array}$ \\
\hline ITQ-6 $^{\text {a }}$ & 580.4 & $\sim 22-26$ & 1 & 293 & $\sim 1.2$ & 64 \\
SBA-15 & 882 & $\sim 21-26$ & 1 & 293 & $\sim 1$ & 64 \\
KBM-700 $^{\text {a }}$ & 1241 & - & 1 & 273 & 4.5 & 65 \\
PR3-700 $^{\mathrm{b}}$ & 826 & 33.3 & 1 & 273 & 4.6 & 1 \\
PAF-450 $^{\mathrm{c}}$ & 1191 & 27.8 & 1 & 273 & 4.5 & 66 \\
KLB2 $^{\mathrm{d}}$ & 1122 & 31 & 1 & 273 & 6.3 & 41 \\
MSC-0.3-900 & 1398 & 28 & 1 & 273 & 6.7 & Present work \\
\hline
\end{tabular}

${ }^{a}$ Nitrogen-doped porous carbons; ${ }^{b}$ Activated carbon beads; ${ }^{c}$ Porous aromatic framework; ${ }^{d}$ Activated bio-carbons 


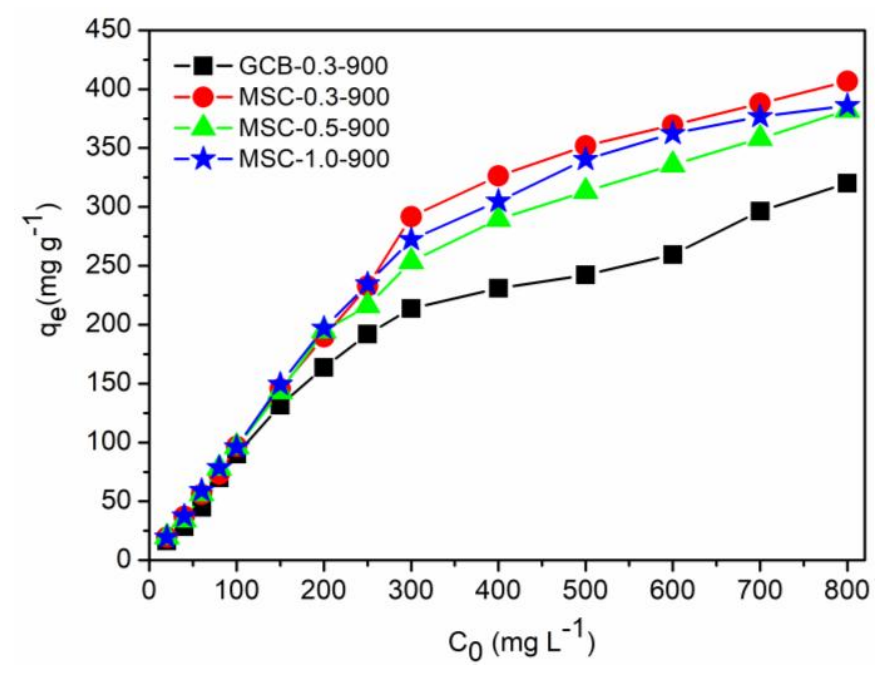

Fig. 10 Adsorption behavior of activated carbon beads in decontamination of OTC from aqueous solutions with different concentrations (adsorption time: $12 \mathrm{~h}$, adsorption temperature: $25^{\circ} \mathrm{C}$; $\mathrm{C}_{0}=20-800 \mathrm{mg} \mathrm{L}^{-1}$; Dose of adsorbents: $1 \mathrm{~g} \mathrm{~L}^{-1}$ ). maximum adsorption capacity calculated from the Langmuir model (Table 3). It is worth noting that the differences between the carbon beads obtained from MSC-derived resins (MSC-0.3-900, MSC-0.5-900 and MSC-1.0-900) are not substantial. In the case of OTC adsorption, the available specific surface area is the key factor controlling the OTC adsorption, in contrast to the $\mathrm{CO}_{2}$ adsorption where the type of pores is a crucial issue. It is noteworthy that sulfur resided in the pore structure increases the surface chemical polarity, thus, favoring adsorption of organic polar pollutants. ${ }^{17,18}$

In order to shed more light on the relationship between the adsorption capacity and the equilibrium concentration in water, the OTC adsorption isotherms were further analyzed by Langmuir and Freundlich models, following the method reported previously. ${ }^{64}$ The linear regressions of the fitting results are shown in Fig. $\mathrm{S} 8$ and the calculated parameters of these models are listed in Table 3. Among these models, the Langmuir model $\left(R^{2}>0.97\right)$ is the best-fitted one. The collected data points out that the adsorption of OTC molecules on activated carbon beads takes place as monolayer adsorption and there is a homogeneous interaction between the surfaces of the activated carbon beads and the OTC. ${ }^{65}$

Table 3 Langmuir and Freundlich isotherm constants for the OTC adsorption on activated carbon beads at $25^{\circ} \mathrm{C}$

\begin{tabular}{|c|c|c|c|c|c|c|}
\hline \multirow[b]{2}{*}{ Adsorbents } & \multicolumn{3}{|l|}{ Langmuir } & \multicolumn{3}{|l|}{ Freundlich } \\
\hline & $\mathrm{q}_{\max }\left(\mathrm{mg} \mathrm{g}^{-1}\right)$ & $\mathrm{K}_{\mathrm{L}}\left(\mathrm{L} \mathrm{mg}^{-1}\right)$ & $\mathrm{R}_{\mathrm{L}}^{2}$ & $\begin{array}{l}\mathrm{K}_{\mathrm{F}}\left(\mathrm{mg} \mathrm{g}^{-1}\right) \\
\left(\mathrm{L} \mathrm{mg}^{-1}\right)^{1 / \mathrm{n}}\end{array}$ & $n$ & $\mathrm{R}_{\mathrm{F}}^{2}$ \\
\hline GCB-0.3-900 & 322.6 & 0.02 & 0.979 & 10.94 & 3.59 & 0.950 \\
\hline MSC-0.3-900 & 416.7 & 0.06 & 0.995 & 12.81 & 4.36 & 0.789 \\
\hline MSC-0.5-900 & 384.6 & 0.05 & 0.986 & 12.41 & 4.35 & 0.883 \\
\hline MSC-1.0-900 & 384.6 & 0.09 & 0.996 & 12.97 & 4.84 & 0.774 \\
\hline
\end{tabular}

\section{Conclusions}

Activated carbon beads were prepared by employing two types, gel-type microporous (GCB) and macroporous (MSC), cation exchange resin beads as precursors. The precursor beads were first exchanged to potassium which serves as an activator of the carbonization reaction in the following high temperature step. The potassium efficiently generates pores upon carbonization and the final carbon structure strongly depends on the concentration of potassium and the type of resin beads used. After the activation, the $\mathrm{K}^{+}$can be completely removed by acid washing. The best results in term of high specific surface area, large micropore volume with narrow pore size distributions and retained spherical morphology were obtained with MSC resin beads exchanged with $0.3 \mathrm{M} \mathrm{KCl}$ solution and carbonized at $900{ }^{\circ} \mathrm{C}$. The obtained activated carbon beads exhibit excellent $\mathrm{CO}_{2}$ adsorption capacities at both ambient and elevated pressures. The excellent $\mathrm{CO}_{2}$ adsorption ability is attributed to the appropriate type of micropores (ca. $1 \mathrm{~nm}$ ) and large available sorption surface. The obtained results are amongst the best published in the open literature. The carbon beads also showed the excellent capability of medical pollutant sequestration from aqueous solutions. The application of shaped activated carbon beads produced according to the present method can certainly be extended to other adsorption applications where shaped bodies with high specific surface area, sulfur-containing functional surface and large pore volume are needed.

This simple and efficient method for producing shaped carbon materials with excellent adsorption capabilities can be easily scaled up.

\section{Conflicts of interest}

There are no conflicts to declare. 


\section{Acknowledgements}

Q. F. and V. V. thank the National Natural Science Foundation of China (21571079, 21621001, 21390394, 21571076 and 21571078) for their financial support. V.V. and Q.F. acknowledge the support from the Thousand Talents Program (China).

\section{References}

1 J. Liu, N. Sun, C. Sun, H. Liu, C. Snape, K. Li, W. Wei and Y. Sun, Carbon, 2015, 94, 243-255.

2 M. Tagliavini, F. Engel, P. G. Weidler, T. Scherer and A. I. Schafer, J. Hazard. Mater., 2017, 337, 126-137.

3 P. Nugent, Y. Belmabkhout, S. D. Burd, A. J. Cairns, R. Luebke, K. Forrest, T. Pham, S. Ma, B. Space, L. Wojtas, M. Eddaoudi and

M. J. Zaworotko, Nature, 2013, 495, 80-84.

4 K. J. Choi, S. G. Kim and S. H. Kim, J. Hazard. Mater., 2008, 151, 38-43.

5 F. Su, C. Lu, S.-C. Kuo and W. Zeng, Energy Fuels, 2010, 24, 14411448.

6 M. Kazemimoghadam, Desalination, 2010, 251, 176-180.

7 V. Valtchev, J. Mater. Chem., 2002, 12, 1914-1918.

8 S. Araki, H. Doi, Y. Sano, S. Tanaka and Y. Miyake, J. Colloid Interface Sci., 2009, 339, 382-389.

9 J. Tao, J. Xiong, C. Jiao, D. Zhang, H. Lin and Y. Chen, ACS Sustainable Chem. Eng., 2015, 4, 60-68.

10 Y. Zhao, X. Liu and Y. Han, RSC Adv., 2015, 5, 30310-30330.

11 A. J. Brooks, H. N. Lim and J. E. Kilduff, Nanotechnology, 2012, 23, 294008.

12 J. A. Mason, K. Sumida, Z. R. Herm, R. Krishna and J. R. Long, Energy Environ. Sci., 2011, 4, 3030.

13 J. Y. Lee, C. Y. Tang and F. Huo, Sci. Rep., 2014, 4, 3740.

14 J. Przepiórski, M. Skrodzewicz and A. W. Morawski, Appl. Surf. Sci., 2004, 225, 235-242.

15 M. S. Shafeeyan, W. M. A. W. Daud, A. Houshmand and A. Arami Niya, Appl. Surf. Sci., 2011, 257, 3936-3942.

16 D. P. Vargas, L. Giraldo, J. Silvestre-Albero and J. C. MorenoPiraján, Adsorption, 2010, 17, 497-504.

17 J. Rivera-Utrilla, M. Sanchez-Polo, V. Gomez-Serrano, P. M. Alvarez, M. C. Alvim-Ferraz and J. M. Dias, J. Hazard. Mater., 2011, 187, 1-23.

18 A. Bhatnagar, W. Hogland, M. Marques and M. Sillanpää, Chem. Eng. J., 2013, 219, 499-511.

19 S. Lawes, A. Riese, Q. Sun, N. Cheng and X. Sun, Carbon, 2015, 92, 150-176.

20 J. Qi, J. Li, Y. Li, X. Fang, X. Sun, J. Shen, W. Han and L. Wang, Chem. Eng. J., 2017, 307, 989-998.

21 Y. Kim, J. Bae, J. Park, J. Suh, S. Lee, H. Park and H. Choi, Chem. Eng, J., 2014, 256, 475-485.
22 Y. X. Zhuxian Yang, Yanqui Zhu, and Robert Mokaya, Chem. Mater., 2007, 19, 6317-6322.

23 N. Sun, C. Sun, H. Liu, J. Liu, L. Stevens, T. Drage, C. E. Snape, K. Li, W. Wei and Y. Sun, Fuel, 2013, 113, 854-862.

24 Y. Liu, L. D. Nguyen, T. Truong-Huu, Y. Liu, T. Romero, I. Janowska, D. Begin and C. Pham-Huu, Mater. Lett., 2012, 79, 128-131.

25 L. Tosheva, J. Parmentier, V. Valtchev, C. Vix-Guterl and J. Patarin, Carbon, 2005, 43, 2474-2480.

26 F. O. Gaslain, J. Parmentier, V. P. Valtchev and J. Patarin, Chem. Commun., 2006, 991-993.

27 L. Tosheva, J. Parmentier, S. Saadallah, C. Vix-Guterl, V. Valtchev and J. Patarin, J. Am. Chem. Soc., 2004, 126, 1362413625.

28 N. P. Wickramaratne and M. Jaroniec, ACS Appl. Mater. Interfaces, 2013, 5, 1849-1855.

29 C. Shen, J. Yu, P. Li, C. A. Grande and A. E. Rodrigues, Adsorption, 2010, 17, 179-188.

30 Y. Zeng, K. Wang, J. Yao and H. Wang, Chem. Eng. Sci., 2014, 116, 704-709.

31 Y. Zeng, K. Wang, J. Yao and H. Wang, Carbon, 2014, 69, 2531.

32 N. P. Wickramaratne and M. Jaroniec, J. Mater. Chem. A, 2013,1, 112-116.

33 G. Annadurai, R.-S. Juang and D.-J. Lee, Adv. Environ. Res., 2002, 6, 191-198.

34 B. Krüner, A. Schreiber, A. Tolosa, A. Quade, F. Badaczewski, T. Pfaff, B. M. Smarsly and V. Presser, Carbon, 2018, 132, 220-231.

35 X. Deng, T. Wang, F. Zhao, L. Li and C. Zhao, J. Appl. Polym. Sci., 2007, 103, 1085-1092.

36 X. Luo and L. Zhang, J. Hazard Mater., 2009, 171, 340-347.

37 S. Yenisoy-Karakaş, A. Aygün, M. Güneş and E. Tahtasakal, Carbon, 2004, 42, 477-484.

38 K. Bratek, W. Bratek and M. Kułażyński, Carbon, 2002, 40, 2213-2220.

39 Z. Zhu, A. Li, L. Yan, F. Liu and Q. Zhang, J. Colloid Interface Sci., 2007, 316, 628-634.

40 Q. Wang, X. Liang, W. Qiao, C. Liu, X. Liu, L. Zhan and L. Ling, Fuel Process. Technol., 2009, 90, 381-387.

41 G. Singh, I. Y. Kim, K. S. Lakhi, P. Srivastava, R. Naidu and A. Vinu, Carbon, 2017, 116, 448-455.

42 G. Singh, K. S. Lakhi, I. Y. Kim, S. Kim, P. Srivastava, R. Naidu and A. Vinu, ACS Appl. Mater. Interfaces, 2017, 9, 2978229793.

43 J.B. Parra, J.C. de Sousa, Roop C. Bansal, J.J. Pis and J.A. Pajares, Adsorpt. Sci. Technol., 1995, 12, 51-66.

44 E. P. Barrett, L.G. Joyner and P. P. Halenda, J. Am. Chem. Soc., 1951, 73, 373-380.

45 J. P. Olivier, Carbon, 1998, 36, 1469-1472. 
46 B. Viswanathan, P. Indra Neel and T. K. Varadarajan, Methods of Activation and Specific Applications of Carbon Materials, Chennai: Indian Inst. of Technology, 2009.

47 J. Wang and S. Kaskel, J. Mater. Chem. A, 2012, 22, 23710.

48 M.A. Lillo-Rodenas, D. Cazorla-Amoros and A. LinaresSolano, Carbon, 2003, 41, 267-275.

49 N. Shimodaira, J. Appl. Phys., 2002, 92, 902-909.

50 A. Fouladi Tajar, T. Kaghazchi and M. Soleimani, J. Hazard. Mater., 2009, 165, 1159-1164.

51 M. Kwiatkowski, A. Policicchio, M. Seredych and T. J. Bandosz, Carbon, 2016, 98, 250-258.

52 Y. Xia, Y. Zhu and Y. Tang, Carbon, 2012, 50, 5543-5553.

53 Y. Sun, J. Zhao, J. Wang, N. Tang, R. Zhao, D. Zhang, T. Guan and K. Li, J. Phys. Chem. C., 2017, 121, 10000-10009.

54 V. Presser, J. McDonough, S.-H. Yeon and Y. Gogotsi, Energy Environ. Sci., 2011, 4, 3059.

55 M. Sevilla and A. B. Fuertes, Energy Environ. Sci., 2011, 4, 1765.

56 E. A. Hirst, A. Taylor and R. Mokaya, J. Mater. Chem. A., 2018, 6, 12393-12403.

57 H. An, B. Feng and S. Su, Carbon, 2009, 47, 2396-2405.

58 M. Idrees, V. Rangari and S. Jeelani, J. CO2 Util., 2018, 26, 380-387.

59 M. G. Plaza, K. J. Thurecht, C. Pevida, F. Rubiera, J. J. Pis, C. E. Snape and T. C. Drage, Fuel Process. Technol., 2013, 110, 5360.

60 H. M. Coromina, D. A. Walsh and R. Mokaya, J. Mater. Chem. A., 2016, 4, 280-289.

61 B. Adeniran and R. Mokaya, Nano Energy, 2015, 16, 173185.

62 G. Srinivas, V. Krungleviciute, Z. X. Guo and T. Yildirim, Energy Environ. Sci., 2014, 7, 335-342.

63 J. Park, M. Jung, H. Jang, K. Lee, N. F. Attia and H. Oh, J. Mater. Chem. A., 2018, 6, 23087-23100.

64 A. Zukal, I. Dominguez, J. Mayerova and J. Cejka, Langmuir, 2009, 25, 10314-10321.

65 Y. Pan, Y. Zhao, S. Mu, Y. Wang, C. Jiang, Q. Liu, Q. Fang, M. Xue and S. Qiu, J. Mater. Chem. A, 2017, 5, 9544-9552.

66 T. Ben, Y. Li, L. Zhu, D. Zhang, D. Cao, Z. Xiang, X. Yao and S. Qiu, Energy Environ. Sci., 2012, 5, 8370.

67 P. He, K.-G. Haw, J. Ren, Q. Fang, S. Qiu and V. Valtchev, Inorg. Chem. Front., 2018, 5, 2784-2791.

68 Y. Sun, Q. Yue, B. Gao, Q. Li, L. Huang, F. Yao and X. Xu, J. Colloid Interface Sci., 2012, 368, 521-527. 